\title{
Cannabinoids Enriched Extracts from Industrial Hemp Residues
}

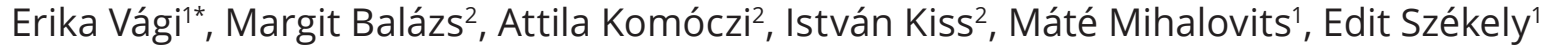 \\ ${ }^{1}$ Department of Chemical and Environmental Process Engineering, Faculty of Chemical Technology and Biotechnology, \\ Budapest University of Technology and Economics, H-1521 Budapest, P.O.B. 91, Hungary \\ 2 Bay Zoltán Nonprofit Ltd. for Applied Research, BAY-BIO Division for Biotechnology, H-6071 Szeged, P.O.B. 2337, Hungary \\ * Corresponding author, e-mail: evagi@mail.bme.hu
}

Received: 22 July 2018, Accepted: 30 October 2018, Published online: 22 March 2019

\begin{abstract}
Obtaining phytocannabinoids, associated with various medicinal and therapeutic properties with no reported side effects, is one of the hot topics. The phychotropic $\Delta^{9}$-tetrahydrocannabinol (THC) is less than $0.2 \%$ in industrial cultivars therefore can be grown legally in many EU countries. Harvesting and processing of hemp for fiber or seeds generates large amount of wastes containing substantial amounts of bioactives such as cannabidiol (CBD) which are the primary cannabinoids along with cannabidiolic acid (CBDA), cannabinol (CBN), cannabigerol (CBG), and cannabichromene (CBC).

The aim of this work was to optimize the extraction of cannabinoids from industrial hemp threshing residue using supercritical carbon dioxide extraction in pilot scales. The effects of extraction pressure and temperature on the extraction yield were evaluated. Three ground and pelleted samples of the same type but with different harvesting time were also compared. After derivatization of the samples the cannabinoids and the minor THCs were quantified by GC-MS. The extraction yields were between $0.2-6.59 \mathrm{~g} / 100 \mathrm{~g}$ dry mass depending on the source of hemp residue and on the process parameters of the extraction process. By increasing the pressure of extraction (in the range of $25-45 \mathrm{MPa}$ at $45^{\circ} \mathrm{C}$ ) the extraction yields increased, meanwhile the yields of cannabinoids showed no significant increase. The volatile compounds were successfully separated from the cannabinoids with fractionated separation. From hemp threshing residues essential oil free extracts with high content of cannabinoids were obtained at $35 \mathrm{MPa}$ extraction pressure and $45^{\circ} \mathrm{C}$ temperature setting the first separator at $8 \mathrm{MPa}$ and $40^{\circ} \mathrm{C}$.
\end{abstract}

\section{Keywords}

circular economy, biomass valorization, Cannabis sativa L., supercritical carbon dioxide, GC-MS

\section{Introduction}

Hemp (Cannabis sativa L.) is one of oldest cultivated annual crops meanwhile it can be also considered as one of the most controversial plant in our society. Industrial hemp is cultivated for products such as fiber for paper and textile, cellulose, hemp seed oil for food, cosmetics and pharmaceutical industries. These industrial cultivars accumulate a minimal amount of $\Delta^{9}$-tetrahydrocannabinol (THC) $(\leq 0.2$ weight $\%)$ therefore they are legally allowed for cultivation also in USA, Canada and in many European countries. During the harvesting and processing large amount of threshing waste is generated, which turned out to be rich in cannabinoids. Cannabis sativa L. has numerous cultivars (which are available for certain purposes such as: high fiber or oil yields, low THC content). Kompolti variety was bred in Hungary especially for high fiber content and it is a variety suitable for local climate and soil. Felina 32 was bred in France for flowers and CBD content and mainly cultivated there [1-3].

Hemp cannabinoids can be classified as non-psychotropic and psychotropic compounds. The $\Delta^{9}-\mathrm{THC}$, its acid (THCA) and its oxidized form the cannabinol (CBN) are all sedative, significantly affecting mental status and highly addictive. $\Delta^{8}$-THC is also psychoactive, although less in extent, and its concentration is also lower [4]. Among more than 90 biologically-active unique cannabinoids, cannabidiol (CBD) is the other primary cannabinoid along with its acid form called cannabidiolic acid (CBDA), cannabigerol ( $\mathrm{CBG})$, and cannabichromene (CBC) which are present in hemp leafy parts in the highest quantities. Numerous studies demonstrate the beneficial medicinal 
and therapeutic properties of these non-pychotropic compounds. CBD and CBDA were shown to exert modulating effects of human endocannabinoid system, they possess analgesic, antibacterial, antidiabetic, antiemetic, antiepileptic, anti-inflammatory, anti-proliferative, antipsychotic properties. Therefore natural products containing cannabinoids are highly desirable as promising agents in treatments of a variety of central nervous system and peripheral disorders (such as Alzheimer's), depression, anxiety, epilepsy, pain and inflammatory diseases $[1,2,4]$.

Along with the bioeconomy strategy of US and Europe there is an obvious scientific and industrial interest in utilizing agro-, food industrial by-products or waste more efficiently. For isolation of high valued compounds different techniques are available from traditional solvent extraction, pressurized liquid extraction, enzyme-assisted / microwave and ultrasound extraction to supercritical extraction (SFE) etc. SFE is an environmentally friendly extraction technique using carbon dioxide as an extraction solvent resulting solvent-residue free extracts rich in lipophilic compounds [5-9]. Supercritical carbon dioxide extraction is widely used for food-, cosmetic-, and pharmaceutical applications especially producing extracts with high added value such as rosehip oil, flavor of hops, medicinal plants. The solubilities of $\Delta^{9}$-THC and two non-psychoactive cannabinoids (CBG and CBD) were studied in supercritical carbon dioxide at different temperature $(315-345 \mathrm{~K})$ and pressure ranges (11.3-25.1 MPa) by Perrotin-Brunel et al. [10, 11]. The solubilities of these three cannabinoids are mainly pressure and less temperature dependent. Two patented technologies exist for extraction of THC and CBD rich hemp extracts using supercritical carbon dioxide extraction. WO2004066277 patent claims procedures applying sub- and supercritical carbon dioxide between 6-60 MPa pressure-, and 10-35 ${ }^{\circ} \mathrm{C}$ temperature ranges with $1000-1500 \mathrm{~kg} / \mathrm{h}$ mass flow of $\mathrm{CO}_{2}$. The patent of US2006247304 focuses on the pain relief with cannabis extracts containing THC and CBD in different ratios. As extraction method it refers back to the content of WO2004066277 patent. In both patents medicinal cannabis plant with high initial THC and CBD concentrations have been extracted after a heating step in which the cannabinoid-acids had converted to THC and CBD with decarboxylation at $100-150{ }^{\circ} \mathrm{C}$. After extraction with sub- or supercritical $\mathrm{CO}_{2}$, winterization (at $-20{ }^{\circ} \mathrm{C}$ temperature for 24 or $48 \mathrm{~h}$ ) is claimed to precipitate the waxy compounds $[12,13]$.
The aim of this study was to compare and to quantify the cannabinoids in the extracts from three different industrial hemp threshing residues using supercritical carbon dioxide extraction at different pressures. The optimization of extraction process obtaining cannabinoid-rich extract at the highest yield was also a scope of this study.

\section{Materials and methods}

\subsection{Hemp residue samples}

The threshing residues used in this study contained the residues of stalks and leaves of hemp. Sample 1 was a Felina 32 type hemp residue harvested in 2014 then pelleted. Sample 2 was a Kompolti type of ground hemp residue harvested in 2014 as well. Sample 3 was a Kompolti type of ground hemp residue harvested in 2016. All samples had $\leq 0.2 \%$ THC content officially certified. The moisture contents of the residues were as follows: Sample 1: $9.77 \pm 0.06(\%, w / w)$, Sample 2: $10.80 \pm 0.32(\% \mathrm{w} / \mathrm{w})$, Sample 3: $18.22 \pm 0.15(\%, w / w)$.

\subsection{Extraction techniques}

The supercritical carbon dioxide extraction was carried out in a pilot plant apparatus with a $5 \mathrm{~L}$ high pressure extraction vessel (supplied by Natex, Austria) equipped with two separation vessels in series. Detailed description of the apparatus can be found in [14]. Liquid food grade carbon dioxide (Biogon C., 99.99 \%, Linde Ltd, Hungary) was used for the extractions. The flow rate of supercritical carbon dioxide set at $7 \mathrm{~kg} / \mathrm{h}$ in all experiments. $500 \mathrm{~g}$ $( \pm 5 \mathrm{~g})$ of hemp residue was loaded into the basket of extraction vessel in each experiment. The extraction temperature was set to $45^{\circ} \mathrm{C}$ based on our preliminary studies not discussed here. The pressure of extraction was varied between $10-45 \mathrm{MPa}$. At extraction with fractionated separation where two separators were connected to the extraction vessel both separators were set at $40^{\circ} \mathrm{C}$, while the pressure of the first separator was higher $(8$ and $9 \mathrm{MPa})$ than that of the second separator (4 MPa). Running the extraction without fractionation, one separator was used at $4 \mathrm{MPa}$ pressure and at $40{ }^{\circ} \mathrm{C}$ temperature, respectively. The extractions ran in batches therefore $\mathrm{CO}_{2}$ was not recycled. According to the moisture content of the actual plant material water was co-extracted, which was decanted, weighted and kept for further analysis. The moisture-free crude extracts were weighted and the yield was calculated as g dry extract / $100 \mathrm{~g}$ d.m. $(\% \mathrm{w} / \mathrm{w})$. The abbreviation d.m. stands for dry material. 


\subsection{Analytical measurements}

All crude extracts were stored at $-20{ }^{\circ} \mathrm{C}$ before sample preparation. The analysis of the target cannabinoids in hemp extracts was carried out by GC-MS analysis with a few modifications, as previously been described [15]. $50 \mathrm{mg}$ crude extract samples were dissolved in head space vial by adding $9 \mathrm{ml}$ methanol and glass beads. Samples were mixed on vortex and sonicated at $40^{\circ} \mathrm{C}$ for $30 \mathrm{~min}$, centrifuged at $4000 \mathrm{rpm}$ for $6 \mathrm{~min}$ and the supernatant was diluted ten and two hundred fold in acetonitrile. $10 \mu \mathrm{l}$ internal standard $\left(10 \mu \mathrm{g} / \mathrm{ml}\right.$ myristic- $\mathrm{d}_{27}$ acid in acetonitrile) and $70 \mu \mathrm{l}$ N,O-bis(trimethylsilyl)trifluoroacetamide (BSTFA) with trimethylchlorosilane (TMCS), 99:1 were added to $10 \mu \mathrm{l}$ sample [16]. The crimp-capped samples were mixed on vortex and heated at $70{ }^{\circ} \mathrm{C}$ for $90 \mathrm{~min}$.

GC-MS analysis of cannabinoids was performed by using an Agilent gas chromatograph (model 6890N) coupled to an Agilent mass spectrometer (model QP-5975). The column was a Rxi-5 Sil MS (Restek) $(30 \mathrm{~m} \times 0.25 \mathrm{~mm}$ $\times 0.25 \mu \mathrm{m})$ the injector was operated in splitless mode at $250{ }^{\circ} \mathrm{C}$. The oven ran from $50{ }^{\circ} \mathrm{C}$ for $1 \mathrm{~min}$ followed by a rate of $30^{\circ} \mathrm{C} / \min$ to $250{ }^{\circ} \mathrm{C}$, hold time was $8.33 \mathrm{~min}$. The carrier gas was helium at flow rate $1.5 \mathrm{~mL} \mathrm{~min}^{-1}$ in constant flow mode. The transfer line was at $250^{\circ} \mathrm{C}$. The mass spectrometer was operated in electron impact (EI) mode at $70 \mathrm{eV}$. The analysis of cannabinoids was performed in SIM mode, three ions for each analyte were acquired. Target and qualifier ions are presented in Table 1.

\section{Results and discussion}

Sequential supercritical carbon dioxide extractions were carried out on Samples 1 and 2. First the extraction pressure was set to $10 \mathrm{MPa}$ and the extraction temperature was $60{ }^{\circ} \mathrm{C}$ to obtain essential oil rich fraction. From the pelleted sample only water was extracted with droplets of yellow oil, while from Sample $20.2 \%$ scented extract was obtained along with 9 times more water using 55-65 kg $\mathrm{CO}_{2} / \mathrm{kg}$ dry material. After the extraction pressure was elevated up to $45 \mathrm{MPa}$, while the extraction temperature was decreased to $45^{\circ} \mathrm{C}$ and extraction was carried on until the rate of extraction set constant. The extraction yields of both samples were presented in the terms of the consumed carbon dioxide ( $\mathrm{kg} / \mathrm{kg}$ d.m.) as shown in Fig. 1. The overall extraction yields were almost the same 5.54 and $5.24 \%$ from Sample 1 and 2, respectively. As Sample 1 was pelleted the mass of consumed carbon dioxide doubled as the mass transfer was limited due to the tightly pressed pellets. At $130 \mathrm{~kg} \mathrm{CO} / \mathrm{kg}$ d.m. solvent usage a
Table 1 SIM parameters for cannabinoid TMS derivatives

\begin{tabular}{lcc}
\hline Analyte & $\begin{array}{c}\text { Target ion } \\
(\mathrm{m} / \mathrm{z})\end{array}$ & $\begin{array}{c}\text { Qualifier ions } \\
(\mathrm{m} / \mathrm{z})\end{array}$ \\
\hline Myristic-d27 (ISTD) & 311 & 312.313 \\
$(-)$-Cannabidiol (CBD) & 301 & 337.390 \\
Cannabichromene (CBC) & 246 & 303.304 \\
$(-)-\Delta^{8}$-THC & 303 & 386.330 \\
$(-)-\Delta^{9}$-THC & 371 & 386.315 \\
Cannabigerol (CBG) & 337 & 338.391 \\
Cannabinol (CBN) & 367 & 368.382 \\
Cannabidiolic acid (CBDA) & 491 & 492.493 \\
THC carboxylic acid A & 487 & 488.489 \\
(THCA-A) & & \\
\hline
\end{tabular}

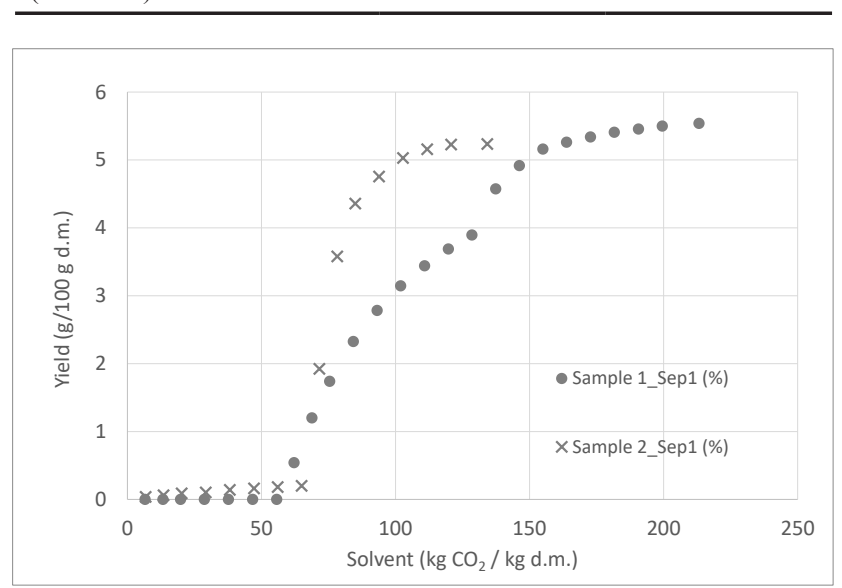

Fig. 1 Extraction yields of Sample 1 and 2 by supercritical carbon dioxide extraction at $10 \mathrm{MPa}$ and $60^{\circ} \mathrm{C}$ first followed by extractions at $45 \mathrm{MPa}$ pressure and $45^{\circ} \mathrm{C}$ temperatures.

slight increase can be seen on the extraction curve, which was caused by an overnight standby under pressure.

Supercritical carbon dioxide extraction with fractionated separation were also performed on both samples at $20 \mathrm{MPa}$ extraction pressure and $45{ }^{\circ} \mathrm{C}$ temperature setting the first separator $9 \mathrm{MPa}$ and $40{ }^{\circ} \mathrm{C}$ and the second separator at $2 \mathrm{MPa}$ and $30^{\circ} \mathrm{C}$. From the Separator 1 waxy, green colored extracts were obtained without any scent, while the extracts from Separator 2 were scented and light brownish colored. The yields of Separator 1 and 2 from Sample 2 are summarized in Fig. 2.

The total extraction yield was $4.96 \%$ with $3.46 \%$ from Sep 1 and $1.50 \%$ from Sep 2 . At the beginning of extraction, the mass transfer rate is constant until it reaches saturation from where the impact of the internal mass transfer is dominant and the rate of extraction decrease. At $20 \mathrm{MPa}$ it reached at $40 \mathrm{~kg} \mathrm{CO}_{2} / \mathrm{kg}$ d.m. solvent consumption.

The major cannabinoids were quantified in the extracts and the results can be seen on Figs. 3 and 4. For better comparison the cannabinoid yields are given as sum of 


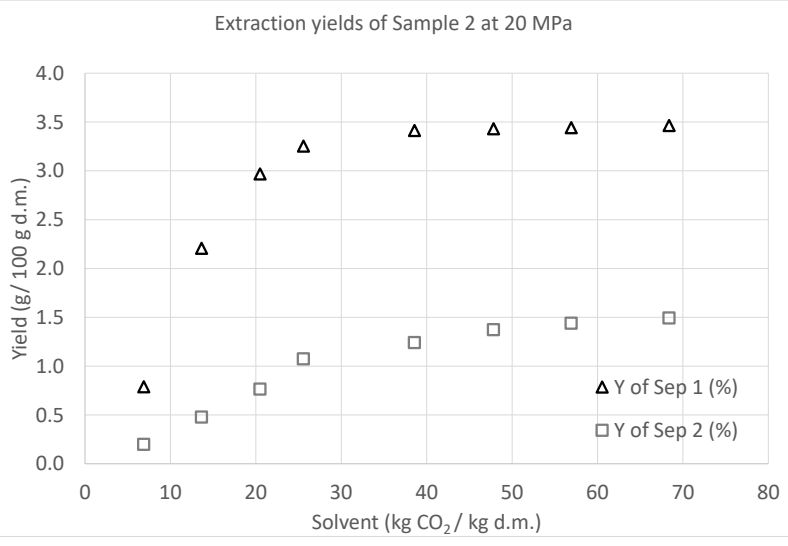

Fig. 2 Extraction yields of Sample 2 by supercritical carbon dioxide extraction at $20 \mathrm{MPa}$ pressure and $45^{\circ} \mathrm{C}$ with fractioned separation

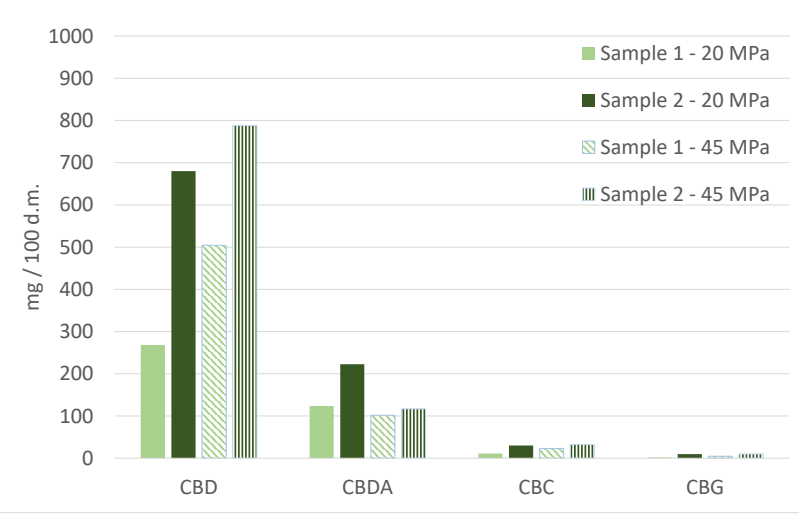

Fig. 3 Non-psychotropic cannabinoids in the extracts from Sample 1 and 2 obtained by supercritical carbon dioxide extraction at 20 and 45 $\mathrm{MPa}$ pressure and $45^{\circ} \mathrm{C}$

the values obtained in the two separators in cases of fractional separation.

Cannabidiol (CBD) and cannabidiolic acid (CBDA) were extracted at higher quantities at $45 \mathrm{MPa}$ than at $20 \mathrm{MPa}$ and it can also be concluded from the results, that these cannabinoids were presented in 1.5-2 times more amounts in the extracts from Sample 2 (116.9 - 788.0 mg / $100 \mathrm{~g}$ d.m.), than from Sample 1. The trends are similar in case of psychotropic cannabinoids: the higher the extraction pressure the more THCs can be extracted. The amounts of $\Delta^{9}$-THC, $\Delta^{8}$-THC, THCA and degradative product (CBN) are also higher in the extracts from Sample 2 , their cumulative yields are between $0.5-18.6 \mathrm{mg} /$ 100 g d.m. These measured amounts are almost 100 times higher than in the officially certified raw materials. In the cumulative extracts both cannabinoids are concentrated and presented together. The amounts of non-psychotropic cannabinoids are 30-42 times higher in the extracts than the amount of THCs. According to literature, CBD

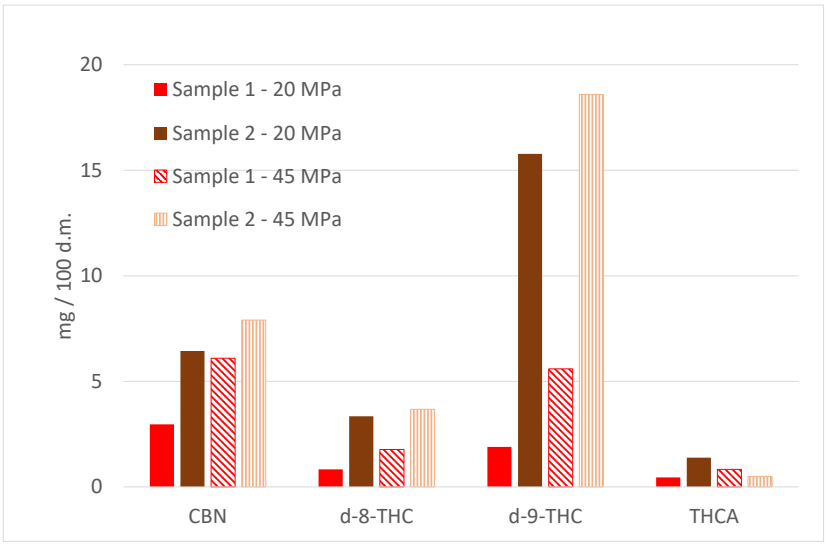

Fig. 4 Psychotropic cannabinoids in the extracts from Sample 1 and 2 obtained by supercritical carbon dioxide extraction at 20 and $45 \mathrm{MPa}$ pressure and $45^{\circ} \mathrm{C}$

antagonizes undesirable side effects of THC. The combination of THC and CBD is now appreciated to have medicinal advantages, although the nature of the interaction is not well and fully understood yet [2].

The effect of extraction pressure on the yield and on the quality of the extracts was also investigated. Supercritical extractions of Sample 3 were carried out at 25, 35 and $45 \mathrm{MPa}$ extraction pressure and at $45{ }^{\circ} \mathrm{C}$ temperature. The two separators were used in series working at $40{ }^{\circ} \mathrm{C}$ and $8 \mathrm{MPa}$ and $2 \mathrm{MPa}$, respectively. The fractions were collected and analyzed separately. Three repetitions were performed at $35 \mathrm{MPa}$ and $45{ }^{\circ} \mathrm{C}$. Fig. 5 shows the extraction curves of three parallel measurements plotted with on the mean with standard deviation.

The effect of extraction pressure on the yield is presented in Fig. 6. There is only a slight increase in the yield from 25 to $35 \mathrm{MPa}$ extraction pressure, while there is no significant increase in yield elevating the extraction pressure from 35 to $45 \mathrm{MPa}$. Waxy, dark green extracts were collected from Sep 1 with yields of $4.75-5.34 \mathrm{~g} / 100 \mathrm{~g}$ d.m., while light brownish yellow colored, scented extracts were recovered from Sep 2 in less than $1 \%$ yield $(0.56-0.75 \mathrm{~g} / 100 \mathrm{~g} \mathrm{~d} . \mathrm{m}$.).

Kitryte et al. [7] also mapped the effect of extraction pressure $(10-50 \mathrm{MPa})$ and temperature $\left(35-70{ }^{\circ} \mathrm{C}\right)$ on the yield from hemp threshing residue. The optimal condition was found to be $46.5 \mathrm{MPa}$ and $70{ }^{\circ} \mathrm{C}$ resulting an extraction yield of $8.3 \%$ (g/ $100 \mathrm{~g} \mathrm{~d} . \mathrm{m}$.) [15]. In contrast, we found that applying the moderate extraction pressure of $35 \mathrm{MPa}$ during the supercritical carbon dioxide extraction of hemp residues is sufficient enough; further pressure increasement do not significantly result in higher extraction yields. Attard et al. [8] examined the effect of extraction pressure (8-40 MPa) and temperature $\left(35-65{ }^{\circ} \mathrm{C}\right)$ on the yield of 


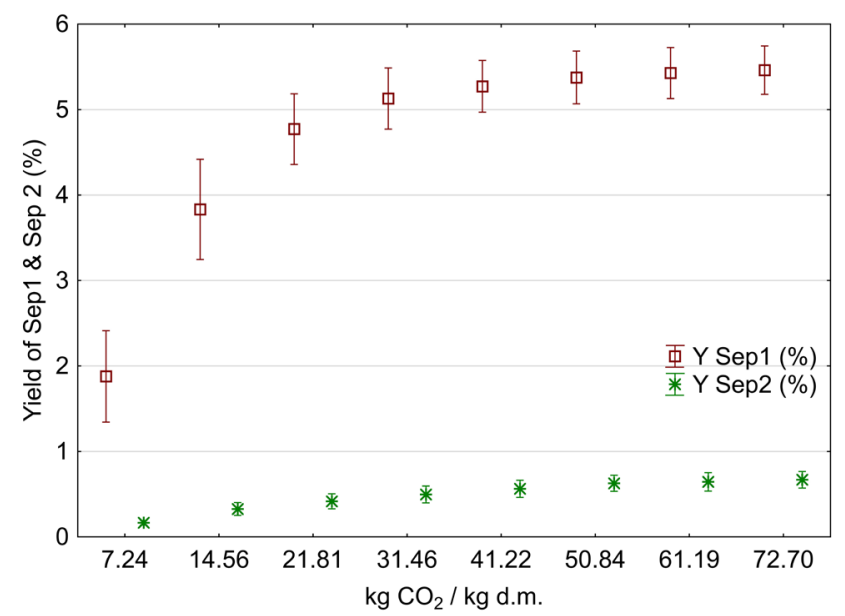

Fig. 5 Mean of extraction yields with standard deviation (SD) at $35 \mathrm{MPa}$ and at $45^{\circ} \mathrm{C}$, two separators connected in series.

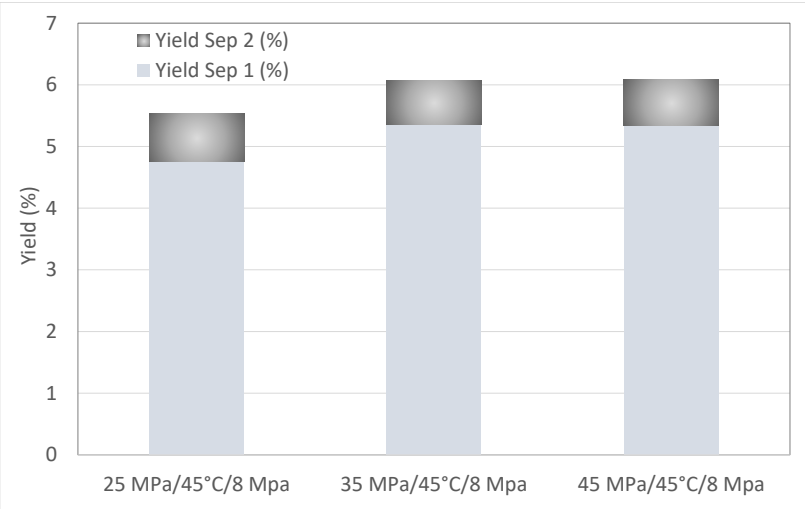

Fig. 6 The effect of extraction pressure on the yield at 25, 35 and $45 \mathrm{MPa}$ pressures at $45^{\circ} \mathrm{C}$

supercritical carbon dioxide extraction of hemp dust, but their maximal yield was 5 times less, $1.87 \%$ (g/ $100 \mathrm{~g}$ dust), than the results shown in this work.

The effect extraction pressure on the yield of cannabinoids can be seen in Figs. 7 and 8 .

In Fig. 7 the yields of each non-psychotropic cannabinoid are summarized. In the highest amount the cannabidiolic acid (CBDA) were extracted $(1.39-1.66 \mathrm{~g} / 100 \mathrm{~g}$ d.m.), and it was measured in the highest quantities in the extracts from the extraction run at $35 \mathrm{MPa}$ extraction pressure and at $45{ }^{\circ} \mathrm{C}$. The yields of cannabidiol (CBD) were between 156.9 - $163.3 \mathrm{mg} / 100 \mathrm{~g} \mathrm{~d} . \mathrm{m}$, which is almost ten times less than the yields of CBDA.

In Fig. 8 the psychotropic cannabinoid yields are summarized in the extracts obtained at 25, 35 and $45 \mathrm{MPa}$ extraction pressure and at $45^{\circ} \mathrm{C}$.

The THCA was obtained in the highest amount (36.6 $-46.1 \mathrm{mg} / 100 \mathrm{~g} \mathrm{~d} . \mathrm{m})$ and its quantity was the highest

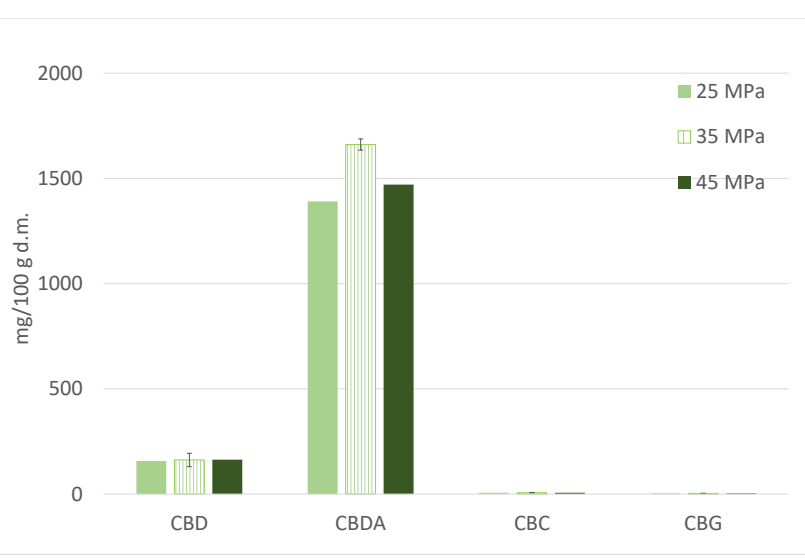

Fig. 7 The effect of extraction pressure on the non-psychotropic cannabinoids in the extracts from Sample 3 obtained at different extraction pressure $(25,35$ and $45 \mathrm{MPa})$.

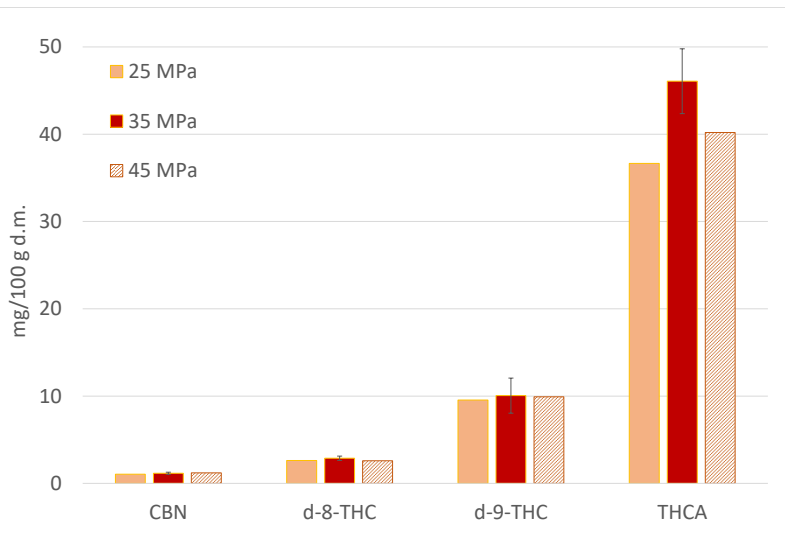

Fig. 8 The effect of extraction pressure on the yields of psychotropic cannabinoids in the extracts from Sample 3

in the extracts obtained in the supercritical carbon dioxide extraction at $35 \mathrm{MPa}$ with a mean of $46.1 \pm 3.7 \mathrm{mg} / 100$ g d.m. yield. The amount of $\Delta^{9}$-THC was at $10.0 \pm 2.0 \mathrm{mg}$ / $100 \mathrm{~g}$ d.m. while the mass of other two compounds were below $3 \mathrm{mg} / 100 \mathrm{~g}$ d.m. The standard deviations plotted on the graphs were calculated from the results of the three parallel measurements, thus those show the combined uncertainty of the extraction and of the chemical analysis. The standard deviations of analytical measurement and the pilot plant scale process are acceptably good. The process is robust and the applied analytical method is accurate.

Comparing the three different samples, it can be concluded that the chemical compositions of Sample 1, 2 and 3 are different. The patterns of cannabinoids in Sample 1 and 2 are similar with some differences in quantities according to the applied process parameters. The main cannabinoid was cannabidiol (CBD) (268.3 - 788.0 mg / 100 g d.m.), while this compound was found in less than $163.3 \mathrm{mg} / 100 \mathrm{~g}$ 
d.m. in Sample 3. Sample 3 contained the cannabidiol acid (CBDA) in the highest amount in $1.66 \mathrm{~g} / 100 \mathrm{~g}$ d.m., while the amount of CBDA was ten times less in Sample 1 and $2(101.9-222.7 \mathrm{mg} / 100 \mathrm{~g}$ d.m.). The higher share of the acid form in the fresh sample is along with the expectations, as the decarboxylation of the acid form the neutral form is a preferred thermal degradation process which also happens during storage $[1,2,12,13]$. Among the psychotropic cannabinoids the patterns of constituents also differ among Sample 1, 2 and 3. In Sample 1 and $2 \Delta^{9}$-THC and its degraded product (CBN) were found in the highest quantities $(0.5-18.6 \mathrm{mg} / 100 \mathrm{~g}$ d.m.). In Sample 3 the amount of $\Delta^{9}$-THC was also $10.0 \pm 2.0 \mathrm{mg} / 100 \mathrm{~g} \mathrm{~d}$.m., while in the extracts from Sample 3 tetrahydrocannabinol-acid (THCA) was found in the highest amount $(36.6-46.1 \mathrm{mg} / 100 \mathrm{~g}$ d.m.). The observation are especially interesting when it is taken into account that the varieties of Sample 1 and 2 were different, while Sample 2 and 3 were both Kompolti varieties but from different harvesting year.

\section{Conclusion}

It has been demonstrated that the supercritical carbon dioxide extraction is a suitable extracting technique to recover cannabinoids from hemp threshing residues. Three threshing residue samples were involved in the study. The supercritical carbon dioxide extraction experiments were carried out in a pilot scales with sequential extractions and fractionated separations as well. The extraction pressure $35 \mathrm{MPa}$

\section{References}

[1] Chandra, S., Lata, H., ElSohly, M. A. (eds.) "Cannabis sativa L . Botany and Biotechnology", 1st ed., Springer, Cham, Switzerland, 2017.

https://doi.org/10.1007/978-3-319-54564-6

[2] Small, E. "Cannabis - A Complete Guide", Taylor \& Francis Group, CRC, Boca Raton, FL, USA, 2017.

[3] IHEMP ${ }^{\mathrm{TM}}$ FARMS "Hemp variety - Felina 32 datasheet", [online] Available at: http://www.ihempfarms.com/PP_Felina32 [Accessed: 17 July 2018]

[4] Citti, C., Braghiroli, D., Vandelli, M. A., Cannazza, G. "Pharmaceutical and biomedical analysis of cannabinoids: A critical review", Journal of Pharmaceutical and Biomedical Analysis, 147, pp. 565-579, 2018.

https://doi.org/10.1016/j.jpba.2017.06.003

[5] Da Porto, C., Decorti, D., Natolino, A. "Separation of aroma compounds from industrial hemp inflorescences (Cannabis sativa L.) by supercritical $\mathrm{CO}_{2}$ extraction and on-line fractionation", Industrial Crops and Products, 58, pp. 99-103, 2014. https://doi.org/10.1016/j.indcrop.2014.03.042

[6] Rovetto, L. J., Aieta, N. V. "Supercritical carbon dioxide extraction of cannabinoids from Cannabis sativa L.", The Journal of Supercritical Fluids, 129, pp. 16-27, 2017. https://doi.org/10.1016/j.supflu.2017.03.014 and extraction temperature $45^{\circ} \mathrm{C}$ are suitable conditions for extracting cannabinoids in high yields. Increasing further the extraction pressure does not increase the yield and the amounts of cannabinoids in the extracts. The amount of cannabinoids in the extracts are strongly depending of the quality of the threshing residue while the share of acid forms and degradation products depend strongly on storage times. The extracts obtained by supercritical $\mathrm{CO}_{2}$ extraction contained $163.3-788.0 \mathrm{mg} / 100 \mathrm{~g}$ d.m. cannabidiol (CBD), 101.9 - 1660.9 mg / 100 g d.m. cannabidiol-acid (CBDA), while other non-psychoactive compounds were presented in less than $32.3 \mathrm{mg} / 100 \mathrm{~g} \mathrm{~d} . \mathrm{m}$. The psychoactive, sedative tetrahydrocannabinol $\left(\Delta^{9}-\mathrm{THC}\right)$ and its acid form (THCA) were also concentrated in the extracts with the following yields: $1.9-18.6 \mathrm{mg} \mathrm{d}-9-\mathrm{THC} / 100 \mathrm{~g}$ d.m. and $0.5-46.1 \mathrm{mg}$ THCA / $100 \mathrm{~g}$ d.m. depending on variety, times of harvesting and extraction conditions as well. Fractionation of the crude extracts was also achieved by two separation vessels in series operated at different pressure. The cannabinoid-rich extracts were concentrated in the first separator, while scented extract was recovered from the second separator.

\section{Acknowledgement}

This work was supported by the Higher Education Excellence Program of the Ministry of Human Capacities in the frame of Biotechnology research area of Budapest University of Technology and Economics (BME FIKP-BIO).

[7] Kitrytè, V., Bagdonaite, D., Venskutonis, P. R. "Biorefining of industrial hemp (Cannabis sativa L.) threshing residues into cannabinoid and antioxidant fractions by supercritical carbon dioxide, pressurized liquid and enzyme-assisted extractions", Food Chemistry, 267, pp. 420-429, 2018.

https://doi.org/10.1016/j.foodchem.2017.09.080

[8] Attard, T. M., Bainier, C., Reinaud, M., Lanot, A., McQueenMason, S. J., Hunt, A. J. "Utilisation of supercritical fluids for the effective extraction of waxes and Cannabidiol (CBD) from hemp wastes", Industrial Crops and Products, 112, pp. 38-46, 2018. https://doi.org/10.1016/j.indcrop.2017.10.045

[9] Brighenti, V., Pellati, F., Steinbach, M., Maran, D., Benvenuti, S. "Development of a new extraction technique and HPLC method for the analysis of non-psychoactive cannabinoids in fibre-type Cannabis sativa L. (hemp)", Journal of Pharmaceutical and Biomedical Analysis, 143, pp. 228-236, 2017. https://doi.org/10.1016/j.jpba.2017.05.049

[10] Perrotin-Brunel, H., Perez, P. C., van Roosmalen, M. J. E., van Spronsen, J., Witkamp, G.-J., Peters, C. J. "Solubility of $\Delta^{9}$-tetrahydrocannabinol in supercritical carbon dioxide: Experiments and modeling", The Journal of Supercritical Fluids, 52(1), pp. 6-10, 2010. https://doi.org/10.1016/j.supflu.2009.12.001 
[11] Perrotin-Brunel, H., Kroon, M. C., van Roosmalen, M. J. E., van Spronsen, J., Peters, C. J., Witkamp, G.-J. "Solubility of non-psychoactive cannabinoids in supercritical carbon dioxide and comparison with psychoactive cannabinoids", The Journal of Supercritical Fluids, 55(2), pp. 603-608, 2010.

https://doi.org/10.1016/j.supflu.2010.09.011

[12] Whittle, B. A., Hill, C. A., Flockhart, I. R., Downs, D. V., Gibson, P., Wheatley, G. W., Gw Pharma Limited "Improvements in the extraction of pharmaceutically active components from plant materials", Great Britain, WO 2004/016277 A2, 2004.

[13] Guy. G., Robson, P. "Pharmaceutical compositions for the treatment of pain", USA, US2006247304 A1, 2006.

[14] Simándi, B., Deák, A., Rónyai, E., Yanxiang, G., Veress, T., Lemberkovics, É., Then, M., Sass-Kiss, Á., Vámos-Falusi, Z. "Supercritical Carbon Dioxide Extraction and Fractionation of Fennel Oil", Journal of Agricultural and Food Chemistry, 47(4), pp. $1635-1640,1999$.

https://doi.org/10.1021/jf9809535
[15] Moore, C., Rana, S., Coulter, C. "Simultaneous identification of 2-carboxy-tetrahydrocannabinol, tetrahydrocannabinol, cannabinol and cannabidiol in oral fluid", Journal of Chromatography B: Analytical Technologies in the Biomedical and Life Sciences, 852(1-2), pp. 459-464, 2007.

https://doi.org/10.1016/j.jchromb.2007.02.016

[16] Harvey, D. J., Paton, W. D. "Use of trimethylsilyl and other homologous trialkylsilyl derivatives for the separation and characterization of mono- and dihydroxycannabinoids by combined gas chromatography and mass spectrometry", Journal of Chromatography A, 109(1), pp. 73-80, 1975. https://doi.org/10.1016/S0021-9673(01)81020-7 